\title{
An Empirical Study about the Vision of a Tutoring Team on the Distance Learning Process
}

\author{
Clauirton A Siebra ${ }^{1}$, Denise Alencar ${ }^{2}$, Ana Paula N Guimarães ${ }^{2}$, Jefferson B Silva ${ }^{2}$ \\ ${ }^{1}$ Laboratory of Applied Artificial Intelligece - Universidade Federal da Paraíba (UFPB) \\ Cep. 58.501-900 - João Pessoa - PB - Brazil \\ ${ }^{2}$ Centre of Informatics - Universidade Federal da Paraíba (UFPB) \\ Cep. 58.501-900 - João Pessoa - PB - Brazil \\ clauirton@di.ufpb.br, dalencarcosta@gmail.com, anapaula@lavid.ufpb.br \\ jefferson.bello@dce.ufpb.br
}

\begin{abstract}
Tutors are a fundamental element of the Distance Learning (DL) process. In fact, they complement the role of lecturers, giving a closer assistance to DL students. Considering the importance of tutors, this work investigates the DL process from their perspective. To that end, an empirical analysis was carried out via questionnaires and interviews, which were applied to 28 distance and 17 local tutors of a DL computing degree course. The collected information was analyzed and classified as a way to stress the main features, problems and solutions that have been applied along the past semesters. A list of suggestions to improve the educational environment/tool and pedagogic method was also elaborated as a result from this research.
\end{abstract}

\section{Introduction}

The term tutor is used as the task title of the person most closely involved in the support of distance learning (DL) students. It is important to observe that the role of tutor for DL students is rather different from traditional course tutor in a number of respects, once distance learning students require a different type of support from that offered to students involved in traditional courses [Daweti 2005]. In fact, the latter are usually studying full time and have access not only to their departmental personal tutor but also to the full range of on campus support services as well as the collaboration of other students. In contrast, distance learners are more likely to be mature people who may have been out of education for many years. They often have responsible and demanding jobs and are studying in isolation, whilst having to balance the demands of employment, study and family life. The support of the personal tutor is thus vital and is often crucial in maintaining both the desire and ability of distance learners to continue with and successfully complete their studies [Nunes at al 2013].

According to the related literature [Lentell 2003, Tait 2004], the tutor has been traditionally under-valued in the process of DL teaching. As discussed by Lentell and O'Rourke (2004) despite several attempts in the research literature to define distance tutor roles, experts have commented critically on the lack of importance assigned to the role of being a tutor at a distance. The same authors argue that "...tutoring tends to be the less visible element of distance education, but is no less essential than good materials 
and effective administration. Distance education cannot exist without tutors who provide feedback and guidance to students".

As a result of this low visibility of the tutor's importance in the learning process, we do not see works that analyze such process from the perspective of the tutors. We argue that this fact represents a big lack in the related literature, once tutors certainly have several perceptions of the process that are not easily captured by lecturers or the administration board of distance learning courses. Based on this argumentation, this work carried out an empirical study to figure out the perceptions of tutors about the distance learning process. The evidences of this study were collected via questionnaires and semi-structured interviews. A similar strategy was used in the work of Stevenson and Sander (1998) to create a report about what students at the Open University (UK) consider as essential qualities of a good tutor. Furthermore, an open discussion, which in known as Focus Group technique by the empirical research literature, was also carried out with a group of tutors to confront diverse opinions and suggestions.

The remainder of this work is structured as follows: Section 2 presents the research method applied to this work, giving details about the information collecting process and object of study. Section 3 presents the results of our investigation, which were consolidated into different main topics and also considering two groups of tutors: distance tutors and local tutors. Finally, Section 4 concludes this work with the main remarks and research directions.

\section{Research Method}

Empirical research methods are a class of research methods that look for extracting relevant data from observations or experience of other persons. In our study, for example, these persons are represented by tutors. In other words, empirical research intends to collect information from sources that have a long experience or knowledge on a subject. Empirical researches can make use of quantitative or qualitative methods. We have decided for the latter methods, once they tend to be more appropriate in the early stages of research (exploratory research) and for theory building. Differently, quantitative methods tend to be more appropriate when a theory is well developed, and for purposes of theory testing and refinement. The next schema (Figure 1) illustrates the steps of our research method.

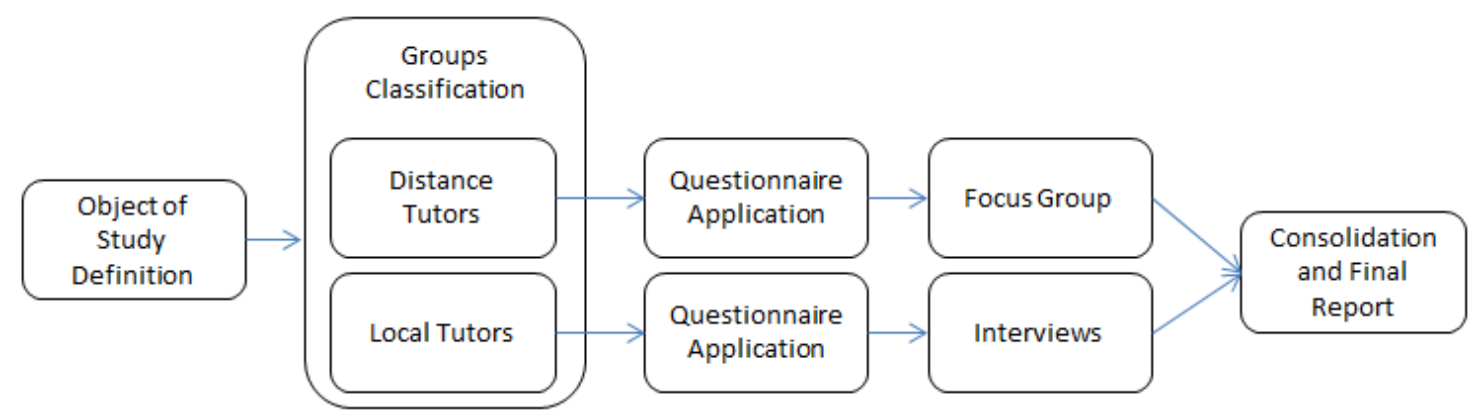

Figure 1. Research steps

The object of study is the Computer Graduation distance learning course of the Federal University of Paraiba (Virtual Unit), which has about 600 students distributed into 14 district units in Paraiba (11), Bahia (2) and Rio Grande do Norte (1) states. The course is 
currently in its fifth period with 25 active disciplines, 34 distance tutors and 23 local tutors. From this total number of tutors, we had the participation of 28 distance and 17 local tutors, which composed two different groups (Figure 1). The role of local tutors is to support students in issues that are not related to contents of disciplines. For example, problems of platform access, applications of exams and so on.

After the groups' classification, we applied a different questionnaire to each group. A questionnaire is a series of written questions that a researcher supplies to subjects, in our case tutors, requesting their response. Usually the questionnaire is selfadministered in that it is posted to the subjects, asking them to complete it and post it back. This was our case. The next questions compose the questionnaire applied to the distance tutors group:

- Which were the main problems faced along your activities as distance tutor?

- Which were the main complains of students?

- How many students were engaged in your discipline and how many accomplished such discipline?

- Was it possible to identify the main reasons to students leaving the discipline?

- Which actions were carried to motivate students that were enrolled in the discipline but without an active participation?

- Which were your main activities as distance tutor? Have you pro-actively performed actions that were considered positive and that would like to share with other tutors?

- Have you faced problem with your lecturer-supervisor? Have you disagreed with some decision or method applied by him/her? Do you think that the material used by the lecturer is adequate?

- Which suggestions could you give to improve the process? Is there some tool that could be integrated to Moodle as a way to improve/support the work of tutors? What could be done to improve the participation of students in your discipline?

The next set of questions composes the questionnaire applied to the local tutors group:

- Which were the main problems faced along your activities as local tutor?

- Which were the main complaints of students?

- How many students do you use to assist? Is there a considerable variation regarding this number at the beginning and end of each semester?

- Which were your main activities as distance tutor? Have you pro-actively performed actions that considered positive and that would like to share with other tutors?

- Is there any problem regarding your relation with the district unit coordination?

- Is there any problem regarding your relation with the university coordination? 
- Were unethical behaviors identified of students during the application of exams? If positive, which were the actions used to avoid such behaviors?

- Are the students of your district asking you questions about the content of some discipline? Which are the disciplines that the students have more difficulty in your opinion?

- Which suggestions could you give to improve the process? Is there some tool that could be integrated to Moodle as a way to improve/support the work of tutors? What could be done to improve the participation of students in your discipline?

After the questionnaires application, we carried out a different strategy to each group. To the local tutors we have carried out interviews based on their answers in the questionnaires. An interview is a series of questions that a researcher addresses personally to respondents. An interview may be structured (where we ask clearly defined questions) or unstructured, where you allow some of your questioning to be led by the responses of the interviewee. This latter approach was used in our study. Our idea was to explore the interviewees' perspectives on the distance learning process in his/her own terms. In this way, we asked questions in a neutral manner, listening attentively to responses and asking follow-up questions based on the interviewees' responses.

To the distance tutors group, we have carried out the Focus Group technique, where a research and several participants meet as a group to discuss a topic. One researcher (the moderator) leads the discussion by asking participants to respond to open-ended questions while takes detailed notes about the comments. We also used a summary of the questionnaires to be discussed with the group, stressing points of confront and good strategies used by some tutors. Thus all group had a broad vision about which was answered in such questionnaires.

All the collected information was consolidated to produce a technical report and distributed among the tutors, lecturers and coordination board. Furthermore, such information was also used to produce this paper, so that other institutions could have access to this research and verify if the knowledge obtained can be useful in their particular contexts and domains.

\section{Results}

The results are discussed into two parts. The first part, Section 3.1, focus on the information collected from the distance tutors group, while Section 3.2 summarizes the information collected from the local tutors group. Such information was consolidated in main topics, which are highlighted along both sections.

\subsection{Distance Tutors Group}

Drop off phenomenon

The drop off rate is probably the main problem in the distance learning process. Tutors have identified this problem and the majority says that, ever using strategies to avoid such drop off phenomenon, their actions are not causing the expected result. In the Calculus discipline, for example, from 90 students, only 10 were approved and about 30 have dropped off. The tutors have also identified an increasing loss of motivation along 
the course and, according to messages of their students, the principal reason is their jobs. This problem works like a snowball. Students give priority to their jobs and family, so that they do not follow the classes and activities at the beginning of the course. Then, without the required initial knowledge, they are not able to properly understand the remainder of the content, which depends on the initial concepts. Tutors also observed that a considerable number of students are enrolled into the curse, but actually they never access the virtual platform. In fact, these students just want to maintain a link with the university as a way to acquire some sort of advantage, such as the student card.

As solution some tutors are making clear in the environment that students that are thinking on dropping off the discipline must schedule a chat to discuss about this decision. This is an interesting solution because tutors will be able at least to know the reasons to such decision. Furthermore, a suggestion of tutors is to extend the Moodle via some type of monitoring tool that generate alerts regarding students that are not participating, accessing or doing the activities in the proper way. Without this tool, tutors need to manually access the reports of each student to identify problems.

\section{$\underline{\text { Level of students }}$}

Tutors have stressed that some students are not able to follow the disciplines because they do not have the proper basis, which they should have acquired along the high school period. This difficult leads some students to a no-ethical behavior, such as plagiarism in their home works.

When a discipline has more than one tutor, it is common that such tutors decide to separate the students in group. Generally the parameters used to separate students are the district unit or alphabetic order. Along the discussions, it was suggested to carry out this separation by the knowledge level of students. In fact, when a tutor is working in a more homogenous group, it is easier to decide for activities and actions that are more adequate to this group. However, this kind of separation requires a previous evaluation of the students' level to identify the components of each group. Furthermore, groups composed of students with more difficulties should be smaller than others because the tutor will certainly have a harder work to perform.

\section{$\underline{\text { Students recurrent complains }}$}

It is clear to tutors that students, mainly in the first periods, are neither familiarized nor feeling comfortable with the dynamic of distance learning process. Thus, it is common that students are always asking for local classed in their districts. In fact these classes must occur, according to the definitions of the Education Ministry for DL, in an average of twice along a period for each discipline. On the other hand, tutors have reported the low participation in such events, when they happen, probably due to the date/time that the classes are scheduled. As the common profile of distance learning students shows that they used to also work, it is hard to schedule periods when a good part of the students are free to participate in such classes.

Some tutors are recording classes and scheduling web conferences as a palliative to the low attendance of traditional classes. By the way, web conferences represent a point of discussion among tutors. While a group says that students prefer web conferences because they feel more comfortable to ask questions and participate along 
the classes, another group says that web conferences do not have the same positive impact than "face-to-face" classes.

Students also complain about the time slot attributed to some disciplines, which are considered more difficult. In fact, the same time slot is attributed to all disciplines. However, tutors has suggested that disciplines that require mathematical and programming skills should have a longer time slot, once students always present more problems to understand the concepts related to such subjects.

Tutors also suggested the implementation of a cognitive balance system, which can be able to monitor the amount of content and activities that are upload by lecturers at each week. The idea is to avoid weeks with overload of content and activities, which is one of the main reasons to decrease the motivation of student with time restrictions, which are currently the majority of distance learning students.

\section{Process of evaluation}

The students' grade is composed of $40 \%$ of activities carried out in the platform and $60 \%$ of local exams in the traditional form. Two exams are performed along the semester to each discipline and, if a student loss one of them, s/he can carry out a reposition exam. A final exam is also provided to students that do not obtained the grade to be approved. The process to apply these four exams is a quite complex. Lecturers must prepare the exams, which are printed and separated according to the number of exams required for each district units. Then, the exams are sent via post office. After the application, the exams are sent back to the university and distributed to the teachers and tutors to evaluation. Only after all this process, the grades are saved in the system and can be visualized by students. According to tutors, this process is a quite stressful to students, mainly when they need to know their final scores to prepare themselves to final exams.

Based on the feedback of tutors about the exams process, this semester we are going to carry out online exams, which will be performed in the own platform. Consequently, teachers and tutor will have immediate access to the exams. Furthermore, some of the questions could be automatically evaluated using the Moodle resources. At this stage, only reposition and final exams will be carried out in an online mode as an initial experiment. After that, we intend to extend this approach to all exams.

Competence of lecturers regarding the distance learning paradigm

Tutors have complained that some teachers are not prepared to act in this educational paradigm. In fact, all lecturers of the course in investigation come from the traditional education and the adaptation is not easy for all of them. A clear example of the lecturers' limitation is the very limited use of the Moodle resources. This platform has several resources that could be explored, such types of activities that could be configured to different contexts. However, lecturers generally only use the basic resources, such as chats, forums, multiple choice questions and sending of files.

These lecturers also account for the production of text books that are used in the disciplines and this is also a problem once the language that must be used is different from text books of traditional courses. Tutors indicated text books that are very short, without the required level of details for students that do not have traditional classes; and also books very complex that do not present the adequate didactic for this kind of learning process. According to tutors, the didactic material should be evaluated by 
specialists in learning education before its publication. This could improve the adequacy of this material. Tutors could also act as reviewers of this material along its use. This review role is very natural, once tutors are applying such material and are able to identify problems of students along the use of such material. Tutors may actually be added as authors of new versions if their suggestions are important in quantity and quality.

Tutors have also complained on the insufficient participation of lecturers in the platform. Some of them only act at the beginning of the course, when the platform is being configured, rather than also interacting to students along the course. A suggestion of tutors is to specify a periodic evaluation process on the lecturers' participation, once the Moodle already provides resources to this monitoring.

A very interesting and useful suggestion of tutors is to provide specialization courses to lecturers about construction and use of learning objects. Digital learning objects are modular and discrete units of learning designed for electronic delivery and use. There is a repository called International Database of Educational Objects, which has, at the moment, 19.838 available learning objects and others 178 that are being evaluated or awaiting their author's authorization to be published. The current total number of access is 6.410 .562 . The advantage of this repository is that it contains free material that was evaluated by experts in the area. Thus, its objects are a rich source to be used in any digital based course. However, to that end, teachers should know the general structure of the objects and how to correctly employ them. Furthermore, the construction of new objects should also be part of the abilities of any lecturer that intends to work in distance learning processes.

Additional issues

Several other suggestions were presented by the group of distance tutors. The most important were:

- Use of ludic resources, such as educational games, and FAQs with summaries about doubts and questions of past semesters;

- Assign extra points to the grades of students that actively participate of local classes;

- Improve the Moodle support for edition of Mathematical equations. Currently, it is more practical to use an external editor, such as Word, to edit the formulas/equations and, after that, transform them in image to be copied and pasted in the Moodle. Note that this is a very bad and inefficient practice;

- Video classes should be more specific rather than approaching several topics and they must be prepared by lecturers once they are supposed to have a more didactic way to transmit knowledge;

- The layout of all disciplines should follow an unique template to assist the use of the environment, mainly by students of the first period.

Some other minor complains were presented, however they were focused on particular features of each discipline and financial aspects of the process, which we do not unfortunately have control or a concrete solution. Thus, they were not presented here. 


\subsection{Local Tutors Group}

Low presence of students in the district unit

Few students use in fact the infra-structure of the district unit. According to the local tutors, the main reason is that the majority of the students are not from the city where the unit is. Some tutors also suggested that the bad quality of the infra-structure is one of the reasons to this low presence of students.

\section{Working as distance tutors}

Local tutors say that several times they are asked by students to assist them about the content of some disciplines and that several students are still presenting a certain resistance in using the Moodle to ask questions and assistance along the course. Thus, some local tutors are trying to organize reinforcement classes and study groups to assist students in disciplines like Calculus. Other technological resources, such as Facebook and WhatsApp are also being used to create groups and support the idea of collaboration among students. The units that are applying this strategy had good results, mainly when their local tutors had a graduation in Mathematics, once such kind of content is the most problematic to students.

It is very important to observe that this continuous search for assistance from local tutors may indicate that the distance tutoring is not working in a proper way. This is a hypothesis that should be investigated in our future works.

\section{Better resources to monitor the performance of students}

Local tutors stressed that they use to have more opportunities to directly interact with students and freedom to talk to them. In other words, as they have more face-to-face interactions with students, local tutors and students are more closed to each other. Based on this fact, some local tutors would like to have more access to tools that could show the status and progress of students regarding their activities and performance along the course. This could assist local tutors in identifying students with problems, so that they could take actions in an early moment. A typical example is when the deadline of activities is close. This tool could identify students that still need to send such activities, so that the tutors could contact them.

\section{Opportunities to improve the level of tutors}

An interesting fact is that the majority of local tutors stressed, during the interviews, that they are enjoying their roles as tutors and they would like to improve their skills in the distance learning area. To that end, some tutors have suggested that the Informatics Post-Graduation Program offers a percentage of their places to local tutors that would like to obtain a Master degree on Informatics in Education. Thus, tutors could investigate and develop dissertations focused on current problems of this learning paradigm and improve their own work as tutors.

\section{Students must feel themselves as part of the university}

According to local tutors, several students do not feel themselves as part of the university. One of the discussed reasons is the low number of local classes. However, a major problem is that several benefits offered to other students are not passed or applied to distance students. For example, DL students do not have access to Extension and 
Scientific Initiation Programs. Other examples are the Monitoring Program and support to the consolidation of Junior Enterprises. Students do not also know details about the Science without Borders program and if they are able to participate in such initiative. In other words, there is still a lack between DL students and the university that must be considered by the coordination of distance learning courses.

\section{Conclusions and Research Directions}

This paper discussed a different vision of the distance learning process, which was taken from the perspective of tutors. The object of study was a computing degree course, which can be considered complex for DL students due to the required mathematical and programming skills. Our investigation stressed several problems and solutions that could be applied to improve the DL process. However, one of the most relevant points is to observe that tutors consider the low adequacy/preparation of lecturers, to act in the DL process, as one of the main problems of this kind of educational paradigm.

As research directions, we intend to deeply analyze and apply some of the suggestions collected along this research. The application of online exams is one action that is already in execution. The use of learning objects also seems to be an important resource to be used by lecturers in their disciplines. In fact, there is an extensive literature on learning objects, including reports of positive experiences that show the potential of this technology [Balatsoukas et al 2010]. The incentive to the creation of study groups is another interesting experience that is bringing very positive results to one of the district units. A more formal evaluation and systematization of this process is another action that we intend to apply in a short future.

\section{References}

Balatsoukas, P., O'Brien, A. \& Morris, A. (2010) "The effects of discipline on the application of learning object metadata in UK higher education: the case of the Jorum repository" Information Research, 16(3) paper 481.

Daweti, A. M. (2005) "Tutoring in Open and Distance Learning - A topical Start-up guide to Distance Education Practice and Delivery", UNISA, Pretoria.

Lentell, H. (2003) "The importance of the tutor in open and distance learning", Tait A., Mills R. (eds.), Rethinking learner-support in distance education, London, RoutledgeFalmer, pp. 64-76.

Lentell, H., O’Rourke, J. (2004) “Tutoring large numbers: an unmet challenge", International Review of Research in Open and Distance Learning, Vol. 5, No 1.

Nunes, V., Albernaz, J., Nobre, I. (2013) A tutoria em uma disciplina do curso superior de Tecnologia em Análise e Desenvolvimento de Sistemas a distância: Avaliação, problemas e busca de soluções. Anais do XXI Workshop sobre Educação em Informática.

Stevenson, K., Sander, P. (1998) "How do Open University students expect to be taught at tutorials?", Open Learning, 13(2): 42-46.

Tait, J. (2004) "The tutor/facilitator role in student retention", Open Learning, 19(1): 97-109. 